\title{
Sleep-related respiratory disturbances in patients with Duchenne muscular dystrophy
}

\author{
F. Barbé*, M.A. Quera-Salva**, C. McCann**, Ph. Gajdos**, \\ J.C. Raphael**, J. de Lattre**, A.G.N. Agustí*
}

Sleep-related respiratory disturbances in patients with Duchenne muscular dystrophy. F. Barbé, M.A. Quera-Salva, C. McCann, Ph. Gajdos, J.C. Raphael, J. de Lattre, A.G.N. Agustí. CERS Journals Ltd 1994.

ABSTRACT: Sleep-related respiratory disturbances (SRD) in patients with muscle diseases may have significant clinical implications, because the patients frequently die at night. The aims of the study were to : 1) assess the presence and severity of sleep-related respiratory disturbances in patients with Duchenne muscular distrophy (DMD); and 2) investigate the relationship of sleep-related respiratory disturbances to daytime symptoms and pulmonary function.

We studied six clinically stable patients with Duchenne muscular dystrophy, mean age $( \pm \mathrm{SD}) 18 \pm 2$ yrs. Vital capacity was $27 \pm 19 \%$ of predicted and daytime arterial oxygen tension $\left(\mathrm{PaO}_{2}\right)$ was $10.9 \pm 1 \mathrm{kPa}$ (range 8.9-12.4 kPa). The presence of daytime somnolence, insomnia, headache, nightmares and/or snoring was recorded.

Four patients $(67 \%)$ showed symptoms that suggest sleep-related respiratory disturbances. At night, the apnoea-hypopnoea index (AHI) was 11 \pm 6 . The patients with more symptoms during the daytime had the highest AHI scores. Most of the apnoeas $(85 \%)$ were central, particularly during rapid eye movement (REM) sleep. Sleep architecture was well-preserved. Arterial desaturation ( $>5 \%$ below baseline) occurred during $25 \pm 23 \%$ of total time. AHI correlated with daytime $\mathrm{PaO}_{2}$, and AHI in REM sleep correlated with age. A stepwise multivariate analysis showed that $\mathrm{PaO}_{2}$ and, to some extent, the degree of airflow obstruction were significantly correlated with AHI.

We conclude that sleep-related respiratory disturbances are frequently present in patients with Duchenne muscular dystrophy. Therefore, physicians should look for symptoms related to sleep-related respiratory disturbances in these patients. Furthermore, sleep-related respiratory disturbances should be strongly suspected in older Duchenne muscular dystrophy patients, particularly if diurnal arterial hypoxaemia is concurrently present.

Eur Respir J., 1994, 7, 1403-1408.
* Servei Pneumología, Hospital Univ. Son Dureta, Palma de Mallorca, Spain. ** Service de Reanimation Medicale, Hopital Raymond Poincaré, Garches, France.

Correspondence: A.G.N. Agustí

Servei de Pneumologia

Hospital Univ Son Dureta 07014 Palma de Mallorca Spain

Keywords: Duchenne muscular dystrophy muscle disease

polysomnography

sleep

sleep-related respiratory disturbances

Received: July 71993

Accepted after revision March 211994

Presented, in part, at the European Respiratory Society Meeting held in London in 1990. FB supported in part by Garches Foundation and ABEMAR.
Duchenne muscular dystrophy (DMD) is a fatal hereditary disease that affects males from early childhood [1]. Patients generally die before the age of $20 \mathrm{yrs}$, mostly because of respiratory complications [2]. These include mucus retention, repeated respiratory infections and impaired gas exchange [3]. There are, however, other respiratory abnormalities that can be easily overlooked in the clinical arena, particularly alterations in the control of ventilation and the presence of respiratory disturbances during sleep [3].

It is generally thought that daytime somnolence and other symptoms related to sleep disturbances are ominous signs that indicate a preterminal state in patients with DMD [4, 5]. However, SмIтн et al. [6] reported, in 1988 , that asymptomatic DMD with normal blood gases can present significant sleep-related respiratory disturbances (SRD). These patients presented frequent apnoeic and hypopnoeic episodes followed by significant arterial oxygen desaturation [6]. Unfortunately, the authors could not identify any daytime index of pulmonary function which would predict the presence and the severity of these SRD. This would be clinically important, since death in DMD patients occurs at night and is unexpected in more than a quarter of cases [7]. The present study was aimed at assessing the presence and severity of SRD in patients with DMD, and at investigating the relationship between the findings recorded at night and both the clinical picture and the results of the pulmonary function tests generally available to the practitioner during the daytime. 


\section{Patients and method}

\section{Population}

We studied six consecutive patients with DMD diagnosed on clinical and muscle biopsy criteria. The age range was 12-22 yrs, with a mean value of 18 yrs. All patients were in a stable clinical condition, without evidence of current respiratory infection. Patient No. 3 had been tracheostomized 8 months before entering the study, during an episode of acute respiratory failure that required mechanical ventilation.

\section{Protocol}

Patients were all studied at the same time of day (10 a.m.), in the sitting position, breathing room air. A questionnaire was used to investigate the presence $(+)$ or absence (-) of symptoms related to SRD. The occurrence of diurnal somnolence, insomnia, headache, nightmares and/or snoring was recorded. Lung mechanics were estimated by measuring forced spirometry (Morgan, UK) according to the American Thoracic Society (ATS) recommendations $[8,9]$. Lung volumes were measured with the helium dilution technique (Morgan, UK). Pulmonary gas exchange was assessed by measuring arterial oxygen tension $\left(\mathrm{PaO}_{2}\right)$, arterial carbon dioxide tension $\left(\mathrm{PaCO}_{2}\right)$ and arterial oxygen saturation $\left(\mathrm{SaO}_{2}\right)$ in a sample obtained anaerobically by direct puncture of the radial artery, after local anaesthesia, whilst the patient was sitting breathing room air (Radiometer Tacussel, ABL 330, Denmark). The alveolar-arterial oxygen gradient $\left(\mathrm{PA}-\mathrm{aO}_{2}\right)$ was calculated according to the standard formula:

$\mathrm{PA}_{-\mathrm{aO}_{2}}=\left(\left(\right.\right.$ barometric pressure-47 $\left.\left.\times \mathrm{FIO}_{2}\right)-\left(\mathrm{PaCO}_{2} / \mathrm{R}\right)\right)$ - $\mathrm{PaO}_{2}$

The respiratory quotient $(\mathrm{R})$ was assumed to be 0.8 ; fractional inspiratory oxygen $\left(\mathrm{FIO}_{2}\right)$ was always 0.21 (room air). On the same night a polysomnographic recording was obtained.

\section{Polysomnographic study}

The polysomnographic recording (Grass 78, Quincy, MA, USA) was obtained at a paper speed of $15 \mathrm{~mm} \cdot \mathrm{s}^{-1}$. The following signals were recorded simultaneously: electroencephalogram (C4-A1 and $\mathrm{C} 3-\mathrm{A} 2$ derivations); electro-oculogram; chin electromyogram; electrocardiogram (modified V2 lead); oronasal flow with thermistors; thoracic and abdominal movements with noncalibrated inductive plethysmography (Respitrace, Ardsley, NY, USA); and transcutaneous $\mathrm{SaO}_{2}$ with finger pulse-oximetry (Biox Ohmeda 3700, USA).

Sleep and sleep stages were scored following the international criteria of RECHTSCHAFFEN and KALEs [10]. Apnoea was defined as a cessation of airflow both at the nose and mouth for at least $10 \mathrm{~s}$. Hypopnoea was defined as a reduction in airflow (longer than $10 \mathrm{~s}$ ), by at least $50 \%$ of baseline, associated with a decrease in $\mathrm{SaO}_{2}$ of more than $4 \%$ from the preceding baseline. Apnoeas were classified as obstructive when thoracic or abdominal movements were present, and as of central origin when these movements were absent.

Several indices of SRD were calculated: 1) the apnoeahypopnoea index (AHI), which is the number of apnoeas plus hypopnoeas divided by the total sleep time (TST) in hours; 2) the rapid eye movement (REM) apnoeahypopnoea index (REM-AHI), which is the AHI during REM sleep; 3) the TST5 and TST10, which correspond to the percentage of TST where $\mathrm{SaO}_{2}$ had fallen more than 5 and $10 \%$ respectively, from baseline; and 4) the sleep efficiency (SE), which is the total sleep time divided by the total time in bed.

\section{Statistical analysis}

Results are expressed as mean \pm standard deviation (SD). The relationship between night-time events and several indices of pulmonary function during daytime was explored using the Pearson correlation test. To explore the relative weight of the different clinical and functional daytime variables in the prediction of SRD, a stepwise multiple regression test (SPSS, Chicago, IL, USA) was used. The AHI was selected as the dependent variable and, as independent variables, we included age, body mass index (BMI), vital capacity (VC) \% predicted, forced expiratory volume in the first second/forced vital capacity ratio $\left(\mathrm{FEV}_{1} / \mathrm{FVC}\right) \%$, total lung capacity (TLC) \% pred, residual volume (RV) \% pred, and the values of diurnal $\mathrm{PaO}_{2}, \mathrm{PaCO}_{2}, \mathrm{SaO}_{2}$ and $\mathrm{PA}_{\mathrm{A}} \mathrm{aO}_{2}$ gradient. A p-value lower than 0.05 was considered significant.

\section{Results}

\section{Clinical status}

Table 1 presents the most relevant clinical data. Age ranged 12-22 yrs, with a mean value of $18 \pm 2$ yrs. The average BMI $\left(19 \pm 5 \mathrm{~kg} \cdot \mathrm{m}^{-2}\right)$ was within the normal range [11]. Four out of the six patients $(67 \%)$ had three or more symptoms related to SRD; diurnal somnolence was not disabling.

Table 1. - Morphometric data and symptomatology referred by the patients

\begin{tabular}{lcccccc}
\hline Patient No. & 1 & 2 & 3 & 4 & 5 & 6 \\
\hline Age yrs & 12 & 20 & 20 & 22 & 15 & 18 \\
BMI kg.m ${ }^{-2}$ & 20 & 26 & 21 & 11 & 16 & 21 \\
Somnolence & - & - & + & + & - & + \\
Insomnia & - & + & + & + & - & - \\
Headache & - & + & + & + & - & - \\
Nightmares & - & + & - & - & - & + \\
Snoring & - & + & - & - & + & + \\
\hline
\end{tabular}

BMI: body mass index; +: symptom present; -: symptom absent. 
Table 2. - Pulmonary function and arterial blood gases

\begin{tabular}{lcccccccc}
\hline Patient No. & 1 & 2 & 3 & 4 & 5 & 6 & Mean & SD \\
\hline $\mathrm{VC} \%$ pred & 38 & 15 & 8 & 10 & 62 & 29 & 27 & 19 \\
$\mathrm{TLC} \%$ pred & 55 & 31 & 32 & 35 & 90 & 50 & 49 & 21 \\
$\mathrm{RV} \%$ pred & 122 & 84 & 136 & 121 & 200 & 122 & 131 & 35 \\
$\mathrm{FEV}_{1} / \mathrm{FVC} \%$ & 91 & 92 & 94 & 94 & 109 & 61 & 90 & 14 \\
$\mathrm{PaO}_{2} \mathrm{kPa}$ & 12.4 & 10.8 & 8.9 & 11.2 & 11.1 & 11.5 & 11.0 & 1.0 \\
$\mathrm{PaCO}_{2} \mathrm{kPa}$ & 5.3 & 5.3 & 6.7 & 4.9 & 4.9 & 4.4 & 5.3 & 0.7 \\
$\mathrm{SaO}_{2} \%$ & 97 & 95 & 93 & 95 & 96 & 96 & 95 & 1 \\
$\mathrm{PA}-\mathrm{aO}_{2} \mathrm{kPa}$ & 0.9 & 2.5 & 2.7 & 2.5 & 2.7 & 2.9 & 2.4 & 0.7 \\
\hline
\end{tabular}

BMI: body mass index; VC: vital capacity; TLC: total lung capacity; RV: residual volume; $\mathrm{FEV}_{1} / \mathrm{FVC}$ : relationship between first second expiratory volume and forced vital capacity; $\mathrm{SaO}_{2}$ : daytime arterial haemoglobin saturation; $\mathrm{PA}_{\mathrm{A}}-\mathrm{aO}_{2}$ : daytime alveolar arterial difference of oxygen tension; \% pred: percentage of predicted value.

\section{Lung function tests}

The results of pulmonary function tests and arterial blood gases are shown in table 2. All patients had severe restrictive ventilatory impairment. Patient No. 6 had both restrictive and obstructive deficiency. The $\mathrm{FEV}_{1} / \mathrm{FVC}$ ratio was increased with respect to normal $(90 \pm 14 \%)$. VC (27 $\pm 19 \%$ pred) and TLC (49 $\pm 21 \%$ pred) were reduced. There was marked air-trapping, with an increased RV (mean $131 \pm 35 \%$ pred).

In contrast, pulmonary gas exchange was relatively well-preserved. $\mathrm{PaO}_{2}$ and $\mathrm{PaCO}_{2}$ were quasi normal in five patients. Patient No. 3 was hypoxaemic $\left(\mathrm{PaO}_{2} 8.9\right.$ $\mathrm{kPa})$ and hypercapnic $\left(\mathrm{PaCO}_{2} 6.7 \mathrm{kPa}\right)$. Interestingly, he had the most severe ventilatory impairment. The mean $\mathrm{PA}_{-\mathrm{aO}_{2}}$ value $(2.4 \pm 0.7 \mathrm{kPa})$ and the diurnal arterial oxygen saturation value $(95 \pm 1 \%)$ were within the normal range.

\section{Sleep respiratory disturbances}

Table 3 presents the individual and mean values of the most relevant variables related to sleep. In general, sleep architecture was relatively well-preserved. Sleep efficiency (SE) was $82 \pm 13 \%$ of total sleep time (TST), and the percentages of the different sleep stages were nor- mally distributed. However, most patients had significant apnoeic and/or hypopnoeic episodes. Five out of the six patients had an AHI greater than 5 (patients Nos 2-6) (table 3). This can be considered abnormal [12]. The majority of apnoeas (85\%) were of the central type. Patients Nos 5 and 6, who had macroglossia and were snorers (table 1), had episodes of obstructive apnoea. The mean duration of the apnoeic episode was 22 s during non-REM sleep and $25 \mathrm{~s}$ during REM sleep. The mean apnoea/hypopnoea ratio was 7 to 1 . In all patients but No. 1, the AHI was higher during REM sleep (table $3)$.

Sinus bradycardia and, occasionally (in patient No. 3), sinusal pauses followed the apnoeic episodes. Also, the apnoeic episodes were generally accompanied by a significant fall in the $\mathrm{SaO}_{2}$ value. $\mathrm{SaO}_{2}$ fell by more than $5 \%$ of baseline during $25 \pm 23 \%$ of TST, (range $0-71 \%$ ), $\mathrm{SaO}_{2}$ fell by more than $10 \%$ of baseline during $9 \pm 11 \%$ of TST (range 0-27\%). More severe oxyhaemoglobin desaturations took place during the REM sleep phase.

\section{Clinical and physiological correlations}

Univariate analysis (Pearson correlation test). We found a negative correlation between the age of the patients (yrs) and vital capacity (\% pred) $(\mathrm{r}=-0.8 ; \mathrm{p}<0.05$; data

Table 3. - Polysomnographic data

\begin{tabular}{|c|c|c|c|c|c|c|c|c|}
\hline Patient No. & 1 & 2 & 3 & 4 & 5 & 6 & Mean & $\mathrm{SD}$ \\
\hline TST $\min$ & 460 & 404 & 264 & 374 & 320 & 432 & 376 & 67 \\
\hline SE \% & 97 & 76 & 55 & 85 & 87 & 89 & 82 & 13 \\
\hline$\% \mathrm{~S} 1$ & 2 & 7 & 35 & 16 & 12 & 22 & 16 & 11 \\
\hline$\% \mathrm{~S} 2$ & 48 & 63 & 52 & 48 & 39 & 33 & 47 & 10 \\
\hline$\%$ S3-4 & 36 & 10 & 10 & 28 & 32 & 27 & 24 & 10 \\
\hline$\%$ REM & 13 & 19 & 3 & 7 & 15 & 16 & 12 & 5 \\
\hline AHI & 2 & 12 & 20 & 9 & 7 & 15 & 11 & 6 \\
\hline AHI-REM & 2 & 102 & 100 & 76 & 40 & 71 & 65 & 35 \\
\hline TST5 & 0 & 35 & 16 & 13 & 17 & 71 & 25 & 23 \\
\hline TST10 & 0 & 21 & 1 & 2 & 1 & 27 & 9 & 11 \\
\hline
\end{tabular}

TST: total sleep time: SE: sleep efficiency; $\% \mathrm{~S} 1, \% \mathrm{~S} 2, \% \mathrm{~S} 3-4, \% \mathrm{REM}$ : percentage of total sleep time spent in different sleep stages; REM: rapid eye movement; AHI: apnoea-hypopnoea index; AHI-REM: AHI in REM sleep; TST5, TST10: percentage of TST with haemoglobin saturation 5\%, 10\% below initial saturation. 

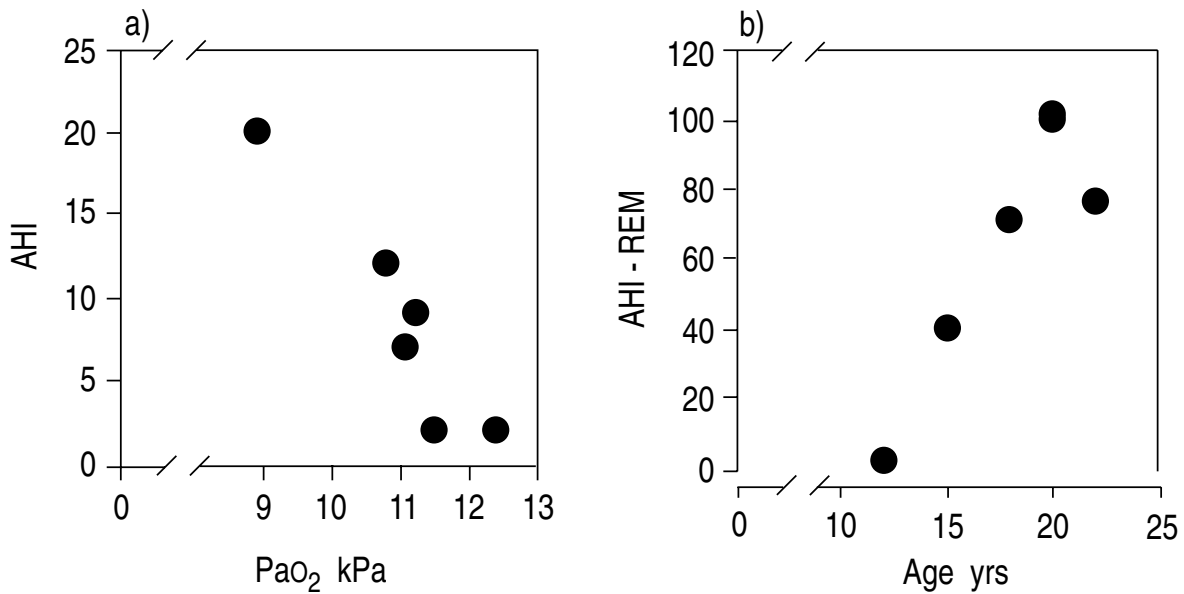

Fig. 1. - Relationship between: a) arterial oxygen tension $\left(\mathrm{PaO}_{2}\right)$ and apnoea-hypopnoea index (AHI); and b) age and apnoea-hypopnoea index during rapid eye movement sleep (AHI-REM). For explanations see text.

a)

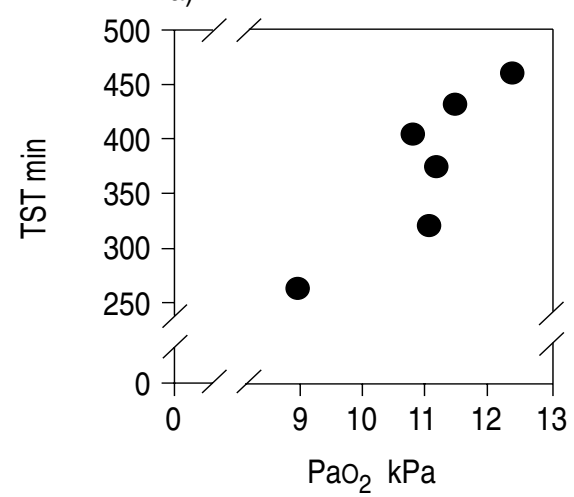

b)

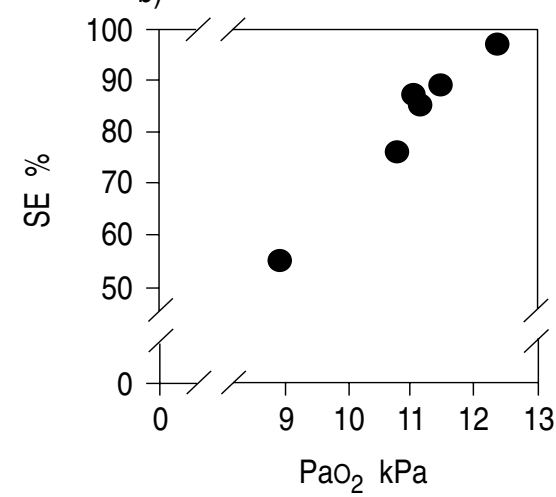

c)

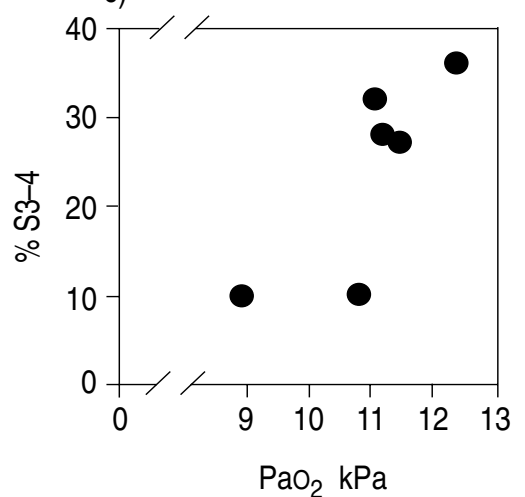

Fig. 2. - Relationship between arterial oxygen tension $\left(\mathrm{PaO}_{2}\right)$ and: a) total sleep time (TST); b) sleep efficiency (SE); and c) the percentage of total sleep time spent in sleep stages 3 and $4(\% \mathrm{~S} 3-4)$. For explanations see text.

not shown), probably reflecting the longer duration of the disease in older patients.

The AHI, as a general index of severity of SRD, was significantly related only to $\mathrm{PaO}_{2}(\mathrm{r}=-0.84 ; \mathrm{p}<0.05)$ (fig. 1a). It was correlated with age $(\mathrm{r}=0.67), \mathrm{VC}(\mathrm{r}=-0.58)$ and TLC ( $\mathrm{r}=-0.50)$, but the relationship failed to reach statistical significance. However, AHI recorded during REM sleep was significantly correlated with age $(r=0.90 ; p<0.05)$ (fig. 1b). Interestingly, several indices of sleep quality were also related to $\mathrm{PaO}_{2}$ (fig. 2): $\mathrm{PaO}_{2}$ was significantly correlated to TST (fig. 2a); SE (fig. 2b); and the percentage of quiet sleep (stages 3 and 4) over TST (fig. 2c).

Stepwise multivariate analysis. $\mathrm{PaO}_{2}$ and $\mathrm{FEV}_{1} / \mathrm{FVC}$ were the only parameters included in the equation as independent predictors of $\mathrm{AHI}(\mathrm{p}<0.002)$. None of the other variables considered a priori (age, BMI, VC, TLC, RV, $\mathrm{PaCO}_{2}, \mathrm{SaO}_{2}$ and $\mathrm{PA}-\mathrm{aO}_{2}$ ) were included in the stepwise analysis.

\section{Discussion}

This study shows that patients with Duchenne muscular dystrophy (DMD) often have sleep-related respiratory disturbances (SRD). In our series, 5 out of 6
DMD patients had apnoea and hypopnoea episodes that were followed by significant falls in arterial oxygen saturation. These SRD can be totally asymptomatic and/or minimized by the patients and relatives. The apnoeahypopnoea index was basically related to daytime $\mathrm{PaO}_{2}$ and, to a lesser extent, to age (figs. 1 and 2). Although the small number of patients studied in this series preclude the drawing of unquestionable guidelines, the results presented extend previous data in patients with DMD [6], and suggest that clinicians caring for DMD patients should intentionally look for SRD, particularly in relatively "old" patients with arterial hypoxaemia. Confirmation of these recommendations will require future studies in a larger series of patients.

The presence and severity of SRD in DMD have seldom been investigated. Most reports have evaluated only $2-3$ patients $[13,14]$, and one included a substantial number of patients with other restrictive diseases [13]. So far, only SмIтн et al. [6] have published a homogeneous series of 14 patients with DMD. Nine of the $14(64 \%)$ presented periodic arterial oxygen desaturations, generally associated with episodes of hypopnoea. Their mean AHI was 9.6 \pm 1 [6]. Our series yielded similar results, with an incidence of SRD in 5 out of 6 DMD patients, and a mean AHI of $11 \pm 6$ (table 3 ). 
In contrast to the study of SMITH et al. [6], four out of the six patients reported here had symptoms related to SRD (table 1). They were those with higher AHI (patients Nos 2, 3, 4 and 6) (tables 1 and 3). Age, arterial blood gases, lung function tests and the hypnogram were similar in our series and in that of Sмітн et al. [6]. Therefore, the differences are not due to differences in patients selection and severity of the disease. We believe that the particular clinical situation of DMD patients and the subtle nature of most of these symptoms can explain the differences. In other words, these are severely disabled patients, who generally stay in bed or wheelchair for almost $24 \mathrm{~h} \cdot$ day $^{-1}$. Thus, it is not surprising that symptoms, such as somnolence (or insomnia), snoring and/or nightmares (table 1), can be easily overlooked by the patient himself, his relatives and/or even the clinician. From these results, we propose that clinicians caring for patients with DMD should intentionally look for symptoms that may indicate the presence of SRD.

Overall, our patients had a relatively well-preserved sleep architecture, as reported previously [6]. The different sleep stages were normally distributed (table 3 ) and sleep efficiency was high $(82 \pm 13 \%)$. This preservation of sleep architecture can also partially explain the mildness of daytime symptoms. It is well-known that diurnal sleepiness relates to sleep architecture disruption and that the latter depends directly on the frequency of arousals [15]. On the other hand, arousals are related to the severity of arterial hypoxaemia [16] and hypercapnia [17], but, more importantly, to the changes of intrathoracic pressure generated by the contraction of the diaphragm [18]. Presumably, the latter is minimal or nonexistent in patients with DMD because of the myopathy. Thus, in the context of severe diaphragm weakness, a lack of sleep architecture disruption (as observed in patients with DMD, even in the presence of significant SRD) can be expected.

Most of the apnoeic and hypopnoeic episodes detected in our patients were of the central type. However, we also observed obstructive apnoeas in two of the six patients (subjects Nos 5 and 6). Interestingly, they were both snorers (table 1) and had macroglossia. Therefore, we suggest that the examination of the oral cavity should always be performed in patients with DMD, particularly when SRD are suspected.

We observed a significant increase in the AHI during REM sleep (table 3). This is not surprising, because it is known that the number of apnoeas and hypopnoeas increases during REM sleep [19]. During REM sleep the contribution of the intercostal muscles to tidal volume decreases from 43 to $19 \%$ [20]. Under these conditions, the diaphragm is basically the only active respiratory muscle [20]. Therefore, diaphragmatic weakness in DMD patients may contribute to the significant increase of AHI observed in our patients during REM sleep (table 3).

Apparently, the incidence and severity of SRD increases in older DMD patients. As shown in table 3 , the youngest patients (subject Nos 1 and 5) presented the lowest AHI scores. The reverse seems true for older patients (tables 1 and 3 ). In addition, there was a significant cor- relation between age and AHI during REM sleep (fig. 1b). Sмiтн et al. [6] found that, even within the limited age range of the population investigated, subjects with nocturnal desaturations tended to be older than those without them. This relationship probably reflects the weaker muscle force of older subjects with more advanced disease. In practice, therefore, we propose that SRD should be intentionally sought in every "old" DMD patient.

In patients with DMD, both VC and TLC are considered survival indices, because they accurately reflect muscle function [21]. In our study, the univariate analysis showed that neither VC nor TLC were significantly related to the AHI. However, the multivariate analysis suggests that the degree of airflow limitation assessed by the $\mathrm{FEV}_{1} / \mathrm{FVC}$ ratio might contribute independently to the prediction of the AHI in these patients. This observation may have clinical relevance, and DMD patients with airflow limitation can be at risk of developing SRD. However, as shown in table 2, only one patient had lower than normal $\mathrm{FEV}_{1} / \mathrm{FVC}$. Therefore, the clinical relevance of this interpretation requires confirmation. On the other hand, $\mathrm{PaO}_{2}$ was the respiratory parameter that was correlated with more indices of SRD and the first one included in the multivariate equation during the building process. Whether arterial hypoxaemia predisposes to SRD in patients with DMD remains to be established.

Previous studies [6] could not identify any single daytime pulmonary function measurement which would predict the presence of SRD. Our data suggest that DMD patients with diurnal arterial hypoxaemia and some degree of airflow limitation are more prone to develop SRD. Two main reasons can explain such discrepancies. Firstly, previous studies did not use correlation techniques (univariate or multivariate). They compared mean pulmonary function test values of two subgroups of subjects (with and without nocturnal desaturations) [6]. Secondly, and probably more importantly, all the patients investigated by SмIтн et al. [6] had normal daytime $\mathrm{PaO}_{2}$ values [6]. By contrast, the subjects reported here showed a range of diurnal $\mathrm{PaO}_{2}$, from 8.9-12.4 kPa.

Our results thus show that sleep-related respiratory disturbances are frequent in Duchenne muscular dystrophy patients. The symptoms (headache, somnolence, etc.) have to be searched for intentionally because they can be easily overlooked. Whenever they appear, a polysomnographic recording at night is warranted. However, even in the absence of such symptomatology, sleep-related respiratory disturbances should be suspected and searched for in old Duchenne muscular dystrophy patients, particularly if they have arterial hypoxaemia and airflow limitation.

Acknowledgements: The authors are grateful to M.J. Lahoz for her secretarial assistance.

\section{References}

1. Gardner-Medwin D. The natural history of Duchenne muscular dystrophy. In: Wise G, Blaw M, Procopis PG, eds. Topics in Child Neurology. New York, Spectrum, 1983; 2: pp. 17-29. 
2. Inkley SR, Oldenburg FC, Vignos PJ. Pulmonary function in Duchenne muscular dystrophy. Am J Med 1974; 56: 297-306.

3. Smith PEM, Calverley PMA, Edwards RHT, Evans GA, Campbell EJ. Practical problems in the respiratory care of muscular dystrophy. N Engl J Med 1987; 316: 1197-1205.

4. Newson Davis J, Loh L. Alveolar hypoventilation and respiratory muscle weakness. Bull Eur Physiopathol Respir 1979; 15 (Suppl. 45-51).

5. Cummiskey J, Lynne Davies P, Guilleminault C. Sleep study and respiratory function in myotonic dystrophy. In: Guilleminault C, Dement WC, eds. Sleep Apnea Syndromes. New York, Alan R. Liss, 1978; pp. 295-308.

6. Smith PEM, Calverley PMA, Edwards RHT. Hypoxemia during sleep in Duchenne muscular dystrophy. Am Rev Respir Dis 1988; 137: 884-888.

7. Rideau Y, Gatin G, Bach J, Gines G. Prolongation of life in Duchenne muscular dystrophy. Acta Neurol (Napoli) 1983; 5: 118-124.

8. American Thoracic Society. Snowbird workshop on standarization of spirometry. Am Rev Respir Dis 1979; 119: 831-838.

9. American Thoracic Society. Standarization of spirometry: 1987 update. Am Rev Respir Dis 1987; 136: 1285-1298.

10. Rechtschaffen A, Kales A. A manual of standardized terminology techniques and scoring systems for sleep stages. Washington DC, US Government Printing Office, 1968.

11. Khoslat T, Lowe FR. Indices of obesity derived from body weight and height. Br J Prev Soc Med 1967; 21 : 122-128.

12. Guilleminault C, Dement WC. Sleep apnea syndromes and related sleep disorders. In: Williams RL, Karacan I, eds. Sleep Disorders: Diagnosis and Treatment. New York, Wiley, 1978

13. Bye PT, Ellis ER, Issa FG, Donnelly PM, Sullivan CE. Respiratory failure and sleep in neuromuscular disease. Thorax 1990; 45: 241-247.

14. Marcello N, Ortaggio F. Detection of sleep respiratory disturbances by transcutaneous $\mathrm{PCO}_{2}$ and $\mathrm{PO}_{2}$ monitoring in advanced stages of Duchenne muscular distrophy. Cardiomyology 1990; 2: 55-66.

15. Stepanski E, Lamphere J, Badia P, Zorick F, Roth T. Sleep Fragmentation and daytime sleepiness. Sleep 1984; 7: $18-26$.

16. Berthon-Jones M, Sullivan CE. Ventilatory and arousal response to hypoxia in sleeping humans. Am Rev Respir Dis 1982; 125: 632-639.

17. Berthon-Jones M, Sullivan CE. Ventilatory and arousal response to hypercapnia in normal sleeping humans. $J$ Appl Physiol: Respirat Environ Exercise Physiol 1984; 57: 59-67.

18. Gleeson K, Zwillich CW, White DP. The influence of increasing ventilatory effort on arousal from sleep. Am Rev Respir Dis 1990; 142: 295-300.

19. Quera-Salva MA, Guilleminault C, Chevret S, et al. Breathing disorders during sleep in myasthenia gravis. Ann Neurol 1992; 31: 86-92.

20. Tusiewicz K, Moldofsky H, Bryan A, Bryan M. Mechanics of the rib cage and diaphragm during sleep. J Appl Physiol: Respirat Environ Exercise Physiol 1977: 43: 600-602.

21. Rideau Y Jankowski LW, Grellet J. Respiratory functions in the muscular dystrophy. Muscle Nerve 1981; 4: 155-164. 